\title{
التحليل المكاني لظاهرتي الزواج والطلاق في محافظة دهوك (2008 - 2016)
}

$$
\text { زاهدة سلمان حسن }
$$

كلية العلوم الإنسانية، جامعة دهوك

اقليم كردستان العراق
د. مزكين محمد حسن

أستاذ مساعد

كلية العوم الإنسانية، جامعة دهوك

اقليم كردستان العراق

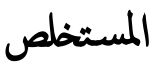

يدرس البحث التباين المكاني والزماني لظاهرتي الزواج والطلاق على مستوى محافظة دهوك ومدنها بالاضافة المى الوقوف على واقح حالات الزواج والطلاق ودراسة هذا الواقع وفق التزكيب العري والنوعي، وتأتي أهمية البحث من كون الظاهرتين لم تخطيا، في دهوك، بدراسات علمية جادة رغ أهميتا في البناء الاجتاعي ومحاوة إيجاد الملول للتقليل من ظاهرة الطلاق. ويفتزض البحث إرتفاع حالات الطلاق خلال فتزة الدراسة ولعدة أسباب منها اجتاعية واقتصادية وغيرها. واتبع البحث المنجج الوصفي والتهليل الكي للبيانات

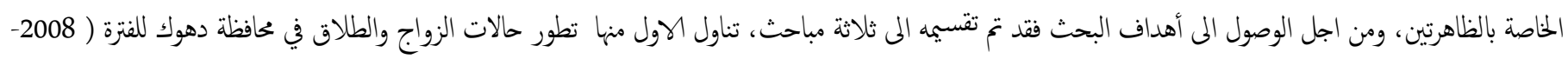
2016)، أما المبحث الثاني فإهتم بدراسة واقع حالات الزواج والطلاق في المحافظة لسنة 2016 ويدرس أولا واقع حلات الزواج والطلاق وفق التريب العمري، وثانيا وفق واقع الزواج والطلاق وفق التزيب النوعي، أما المبحث الثالث فيدرس أهم الأسباب المؤدية الى الطلاق. الكلمات الدالة : تحليل المكلني، الزواج، الطلاق.

1

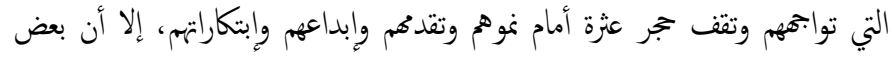
الظواهر السكانية لم تلق لحد الان أي إهتاما جديرا بالذكر والسبب في ذلك هو عدم توفر البيانات الخاصة بتاك الظواهر والمشاكل السكانية التي توابتهمه، وظاهرة الزواج ومشكة الطلاق وتبايهها المكاني أحد تاك المشاكل التي لم تشغل حيزا مكانيا في ذهنية الباحث الجغرافي رغ أهمية الموضوع وتأثيراته الختلفة اجتماعيا واقتصاديا وسياسيا وصحيا، وإنطاقا من هذه الاهمية جاء هذا البحث ليلتي الضوء عليه بهدف تشخيص العوامل المسبة للمشكلة وبيان درجة تأثير العوامل المسبة لها وصولا الى وضع المعالجات الحثيقية في محافظة دهوك وإمكنية تعميها على بقية الحافظات بعد إختبار

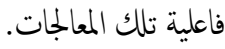

1.1 هدف البحث مهدف البحث الى دراسة التباين المكاني والزماني وواقع الزواج والطلاق في محفظة دهوك للفترة (2008- 2016). 1.2 مشكة البحث تنبع مشكلة البحث من بروز مشكلة الطلاق كظاهرة في المحافظة، ووكها مرتبطة

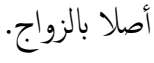

شفل موضوع التباين المكاني إهتام الجنس البشري منذ القدم، والمعروف ان الانسان ومنذ جفر التاريخ لاحظ وسجل هذا التباين الذي شاهده في كل مكان ومن خلالها فكر في أسباب هذا التباين والإختلاف، ومع مرور الزمن لم ميزد في وسائل الملاحظة وقياس الظواهر فسب إنما زاد في قدراته في تشخيص وتسجيل وتصنيف وعرض وتحليل تاك الملاحظاتوها تحولت المعرفة الجغرافية الى مادة مسجلة بدقة وحقائق كمحصة تصور الظاهرات التي تشغل ختلف أنخاء الكرة الارضية. وجغرافية السكان أحد فروع المعرفة الجغرافية إخذت هي الاخرى من التباين المكلني والاختلافات المكانية للخصائص السكنية من حيث توزيعهم وتريسيم وحركتم الطبيعية والمكانية والتنبؤ عنها مستقبلا وتشخيص مشكلاتها الوطنية منها والعلمية وإيجاد الحلول المناسبة لتلافيها ومسرحا لعملياتها السكنية التي كلما توفرت بياناتها بدقة وإنظام حفزت الباحثين والمهتين بأمور السكان في دراسة وتشخيص تاك الظواهر والمشاكل المجلة الكاديمية لجامعة نوروز, المجلد 8, العدد 1 (2019)

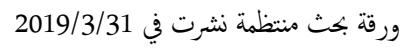

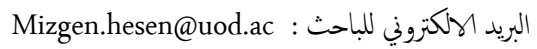
حقوق الطبع والنشر (C) 2017 أسهاء المؤلفين. هذه مقالة الوصول اليها مفتوح موزعة تحت رخصة

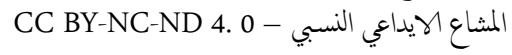


تتطلب السياسة السكانية لكل دولة ان تعد وفقا لاحتياجاته وضمن عملية التنمية الشاملة فيه وان تستهدف في الاساس تحقيق التطور والرفاهية للمجتع، وان الاستراتيجية المعتمدة لتحقيق سياسة زيادة الإنجاب تعني بمحوعة التدابير التي اتخذتها الدولة لتحقيق ننائج في زيادة السكان ويكون قسم منها بشكل قرارات تصدر عن الجهات العليا تشجع الزواج المبكر والإنجاب (هناء محسن العكيلي 1989 : 47).وقد شبجعت الكثير من التشريعات القديمة زيادة النسل والإكثار منه لاسيا نمو وتطور الدولة او بعد خروجحا من الحروب، ويعتبر قانون حمورابي الذي صدر في القرن العشرين قبل الميلاد في بابل أول محاولة تشريعية تهدف الى زيادة النسل إذ نادى ركى بإرتداء الأحات في الأسر الكبيرة الحجم الملابس المميزة والحلي(هناء حسن العكيلي1989 : 41).والجدول (1) والشكل (1 )يبينان هذا التطور خلال الفترة : 2008)
1. هناك تباين واضح في ظاهرتي الزواج والطلاق مكانيا وزمانيا في منطقة الدراسة. 2. تباين درجة تأثير العوامل المسبية للزواج والطلاق بين مناطق المحافظة.

\section{4 حدود البحث}

شمل البحث الحدود الادارية لمحافظة دهوك والواقعة فلكيا بين دائرتي عرض (36 10 44) شرقا وللفترة الزمنية (200 - 2016). 1.5 هيكلية البحث لأجل الوصول الى أهداف البحث، فقد تم تقسيمه الى ثلاثة مباحث، تناول اولما حالات الزواج والطلاق في محافظة دهوك ( 2008 - 2016 )، وإختص الثاني بدراسة تركيب حالات الزواج والطلاق في محافظة دهوك 2016، اما المبحث الثالث فقد إهتم بأهم الاسباب المؤدية الى الطلاق ونسبها. الجدول (1) : التوزيع المكلي للزواج في محافظة دهوك حسب الاقضية (2008 - 2016)

\begin{tabular}{|c|c|c|c|c|c|c|c|c|}
\hline المجموع & زاخو & ئاميدي & الشيخان & بردرش & سميل & نأكري & دهوك & السنة \\
\hline 8790 & 1906 & 814 & 102 & 800 & 632 & 1489 & 3047 & 2008 \\
\hline 8202 & 1761 & 582 & 233 & 724 & 507 & 1410 & 2985 & 2009 \\
\hline 8841 & 1877 & 691 & 177 & 840 & 672 & 1416 & 3168 & 2010 \\
\hline 11446 & 2681 & 772 & 456 & 1139 & 1152 & 1601 & 3645 & 2011 \\
\hline 13849 & 2954 & 1004 & 789 & 1342 & 1358 & 1932 & 4470 & 2012 \\
\hline 14270 & 2985 & 1841 & 372 & 1257 & 1734 & 1753 & 4328 & 2013 \\
\hline 12181 & 2793 & 795 & 544 & 1048 & 1714 & 1572 & 3715 & 2014 \\
\hline 10244 & 2291 & 688 & 495 & 827 & 1143 & 1526 & 3274 & 2015 \\
\hline 9346 & 2139 & 557 & 404 & 892 & 988 & 1347 & 3019 & 2016 \\
\hline 97169 & 21387 & 7744 & 3572 & 8869 & 9900 & 14046 & 31651 & المجمون \\
\hline
\end{tabular}

المصدر : عمل الباحثين بالاعتماد على : حكومة اقليم كوردستان، وزارة العدل، رئاسة إستئناف منطقة دهوك، محكة الاحوال الشخصية في محافظة دهوك، بيانات غير منشورة 
الشكل (1) : التوزيع المكاني للزواج في محفظة دهوك (2008- 2016)

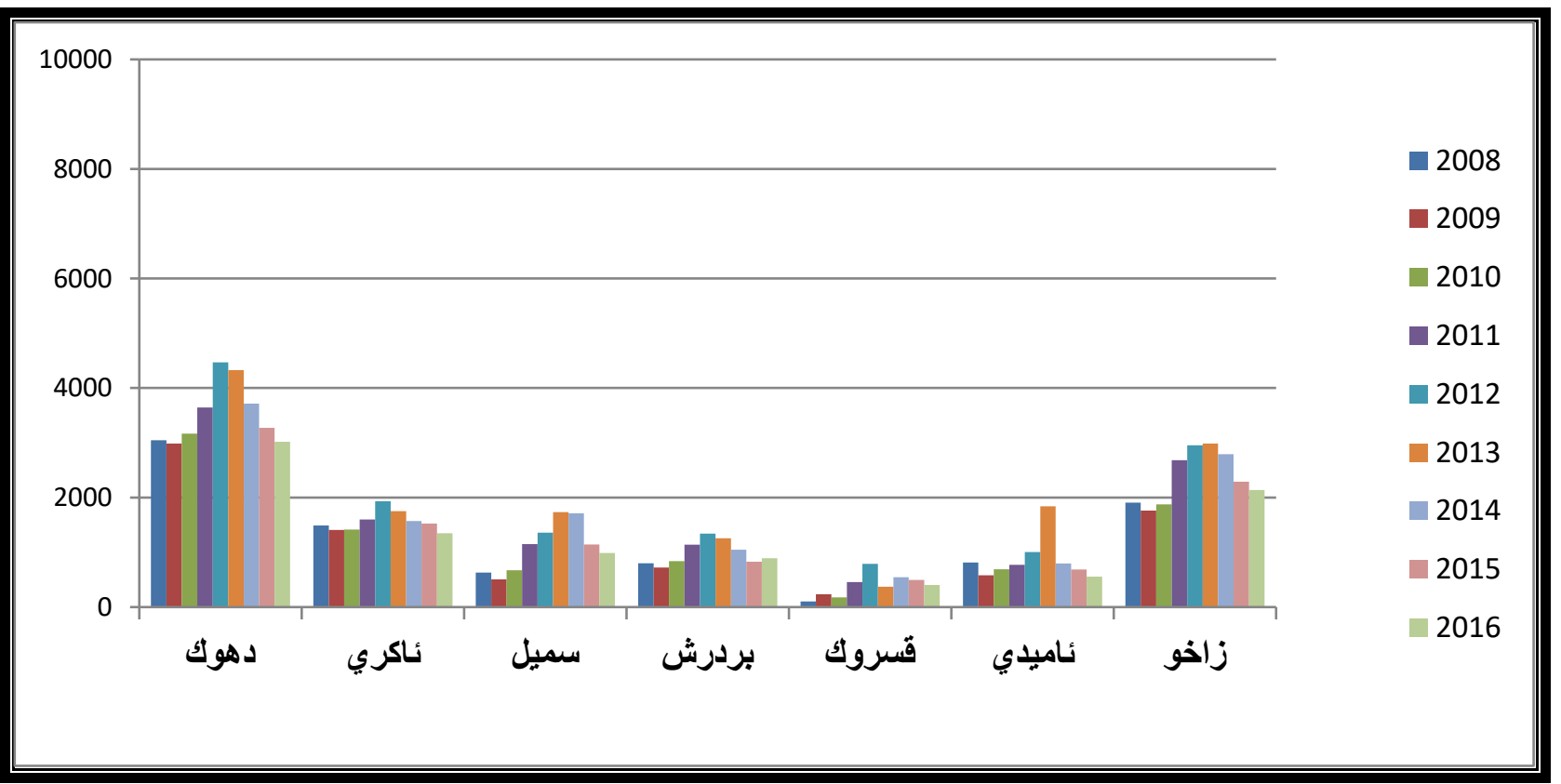

المصدر : عمل الباحثين بالاعتماد على : الجدول (1)

1. سجلت أكثر حالات الزواج في محافظة دهوك في عام 2013 بواقع 14270 حالة المتثلة بسيطرة الارهاب على مناطق في العراق ولم تكن منطقة الدراسة ببعيدة عن ساهمت بنسبة 14.6\% من بموع حالات الزواج لفترة الدراسة، يقابلها أدنى رق سبل هذا الثأثير يضاف الى ذلك توتر العلاقة بين الاقليم وبغداد على خلفية مسألة استخراج وبيع البترول وإجراءات بغداد فيما يخص بموازنة الاقليم وهو ما دفع بحكومتها في العام 2009 بواقع 8202 حالة وبنسبة 9\% فقط. 2. جاء قضاء دهوك في المرتبة الأولى في حالات الزواج في الفتزة المدروسة الى إتباع نظام إدخار رواتب الموظفين الاجباري والذي إنعكس سلبا على الاحوال بواقع31651 حالة شكلت نسبة 32.6\% من مجموع حالات الزواج في المحافظة يليها المميشية للسكان وخصوصا فئة ذوي الرواتب. أما من حيث المعدل المنام للزواج(1) قضاء زاخو بواقع 21387 وبنسبة 22\% وجاءت بعد ذلك ثٔاكري، سميل، بردرش، (عبدالله الطرزي 1991 : 89) في المحافظة فالجدول (2) يوضح هذه المعدلات للفترة ئميدي، الشيخان وبنسب 14.5\%، 10.1\%، 9.1\%، 7.9\%، 3.7\% على المدروسة وهو بشكل عام يتناسب بشكل طردي مع تزايد أعداد السكان وعدد حالات الزواج، مع فارق بسيط في السنوات (2014، 2015، 2016)، كما يكن التوالي. القول بأن هذا المعدل يزداد بدأ من عام 2008 ولغاية عام 2013 بسبب الظروف 3. أما على مستوى الاقضية فقد سجلت أعلى الحالات في قضاء دهوك بواق24470 الاقتصادية والمعيشية التي تحسنت شيئا فشيئا خصوصا مع منح سلف الزواج والتي قدرت بخمسة ملايين دينار عراقي لكل عقد زواج بالاضافة الى السلفة العقارية التي ساهت بشكل فعال في تشجيع الزواج وتكوين الأسر. أما بالنسبة للسنوات (2014، 2015، 2016) فيرجع انخفاض المعدل الى تردي الووضاع المعيشية مقارنة في عام 2012 بنسبة 14.1\% من بموع حالات القضاء للفترة المدروسة وبنسبة 4.6 من بمحوع حالات المحافظة لنفس الفترة.، يقاباها أدنى الحالات وذلك في قضاء الشيخان بواقع 102 حالة فقط في عام 2008 وبنسبة 2.8\% من بموع حالات القضاء وبنسبة0.01\% من بمحوع حالات المحافظة ولنفس الفترة المذكورة. 4. وبطبيعة الحال فإن هذه التذبذبات في تسجيل نسب حالات الزواج يرجع الى بالسنوات السابقة بسبب الظروف الهنية المتمثلة بالحرب على الارهاب وتقليص الظروف المعيشية والاحوال الاقتصادية المستقرة والجيدة في بداية فتزة الدراسة، رواتب الموظفين واجراءات حكومة بغداد تجاه اقليم كوردستان فيه يخص الميزانية. وعلى عكس ذلك في السنوات الاخيرة من تلك الفترة خصوصا بعد الظروف الامنية 
الجدول (2) : معدل الزواج الخام بالألف في محفظة دهوك (2008- 2016)

\begin{tabular}{|c|c|c|c|}
\hline المعدل بالألف & عدد حالات الزواج & عدد السكان & الأعوام \\
\hline 7.7 & 8790 & 1132581 & 2008 \\
\hline 7 & 8202 & 1171231 & 2009 \\
\hline 7.3 & 8841 & 1211053 & 2010 \\
\hline 9.1 & 11446 & 1252229 & 2011 \\
\hline 10.6 & 13849 & 1294804 & 2012 \\
\hline 10 & 13370 & 1336944 & 2013 \\
\hline 8.8 & 12181 & 1379675 & 2014 \\
\hline 7.2 & 10247 & 1423114 & 2015 \\
\hline 6.3 & 9346 & 1467198 & 2016 \\
\hline
\end{tabular}

المصدر : عمل الباحثين بالاعتماد على الجدول(1) و حكومة اقليم كوردستان، وزارة التخطيط، هيئة احصاء الاقليم، مديرية احصاء محافظة دهوك، بيانات غير منشورة عن

إسقاطات السكان.

وعند مقارنة هذه المعدلات مع المعدلات الخاصة بمناطق اخرى فهو يتقارب مع المعدلأو بعضه) بأن يطلقها الطلاق الذي يثبت معه الرجعة (أميرة حسن الرافيي- بدون في العراق( 8.98 عام 2009)، و تركيا(8 عام 2011)، و ايران (12.2 عام 2009)، سنة النشر).والطلاق نوعان هـا : أ. الطلاق الرجعي : ويشمل هذا النوع كل طلاق يوقعه الزوج إلا ماكان على مال

مصر(11 عام 2010 ) (جنار محسن حسن2017 : 12)

او قبل الدخول او مكملا لثلاث (أحمد علي الخطيب 1980 : 136).

2.2 تطور حالات الطلاق في محافظة دهوك ( 2008 - 2016 )

جاء في تعريف الطلاق في المعجم الوسيط : (طلق)- طلوقا وطلاقا، تحرر من قيد ب. الطلاق البائن : وهو كل طلاق قبل الدخول او بمقابل او للمرة الثالثة، وكل وخوه، والمرأة من زوبحا طلاقا : تحلت من قيد الزوج وخرجت من عصمته ويده طلاق رجعي بعد إنتهاء العدة (مصطفى ابراهيم الزلمي 2011 : 103). والجدول (3) بالخير طلقا(رفيق محمد عبدالحكيم الصافي 2011 : 15). أما في الإصطلاح : حل قيد ورالشكل (2) يبينان حالات الطلاق في المحافظة ومنها نجد : النكاح او بصفة وحل قيد النكلح، أي كله بأن يطلق المرأة الطلاق البائن، الجدول (3) : التوزيع المكاني للطلاق في محافظة دهوك (2008 - 2016)

\begin{tabular}{|c|c|c|c|c|c|c|c|c|}
\hline المجموع & زاخو & ثاميدي & الشيخان & بردرش & سميل & نأري & دهوك & القضاء \\
\hline 404 & 95 & 12 & 6 & 42 & 23 & 52 & 174 & 2008 \\
\hline 569 & 151 & 35 & 10 & 37 & 33 & 79 & 224 & 2009 \\
\hline 659 & 169 & 24 & 9 & 65 & 38 & 58 & 296 & 2010 \\
\hline 712 & 177 & 29 & 11 & 52 & 44 & 52 & 347 & 2011 \\
\hline 910 & 234 & 32 & 14 & 70 & 57 & 81 & 422 & 2012 \\
\hline 1053 & 245 & 39 & 23 & 64 & 97 & 71 & 514 & 2013 \\
\hline 1103 & 272 & 28 & 22 & 75 & 105 & 97 & 504 & 2014 \\
\hline 1226 & 332 & 35 & 30 & 57 & 134 & 106 & 532 & 2015 \\
\hline 1261 & 322 & 30 & 20 & 70 & 105 & 99 & 615 & 2016 \\
\hline 7897 & 1997 & 264 & 145 & 532 & 636 & 695 & 3628 & المجموع \\
\hline
\end{tabular}

المصدر : عمل الباحثين بالاعتماد على : حكومة اقليم كوردستان، وزارة العدل، رئاسة إستئناف منطقة دهوك، محكة الاحوال الشخصية في محافظة دهوك، بيانات غير منشورة. 


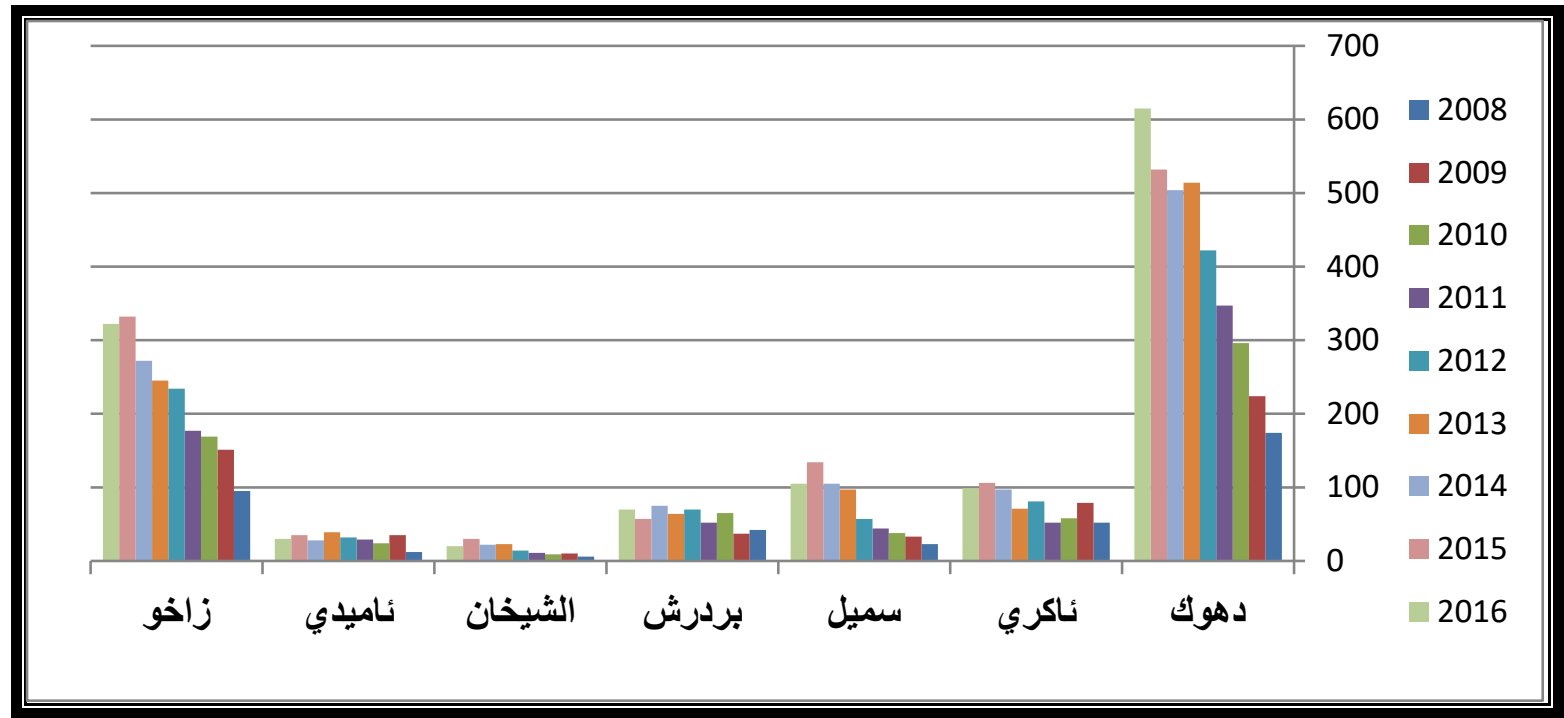

المصدر : عمل الباحثين بالاعتماد على : الجدول (3)

4. أقل الحالات كانت في قضاءي الشيخان وئاميدي وذلك بسبب العادات والتقاليد التي تنبذ الطلاق مع حل الخلافات الزوجية عن طريق تدخل الاهل والأقارب. 5. وبشكل عام فإن السبب وراء هذه النسب يرجع الى عدة عوامل منها سياسية وامنية وعدم الاستقرار بسبب الحرب على الارهاب وما رافقها من اسباب اقتصادية وارتفاع نسب البطالة وهوما يخلق المشاكل الاجتماعية او يكون سببا رئسيا في ارتفاع نسب الطلاق. اما بالنسبة المى معدل الطلاق الخام(2) (جنار محسن حسن2017 : 16) في المحافظة فيبين الجدول (4) تلك المعدلات للفترة المدروسة، وهو يشير الى ارتفاع الحالات سنة بعد أخرى وبشكل طردي مع ارتفاع أعداد السكان. وعند مقارنة هذه المعدلات مع المعدلات الخاصة بمناطق اخرى فهو يقل عن المعدل في العراق( 1.97 عام 2009)، و تركيا(1.6 عام 2011)، و ايران (1.7 عام 2009)، الاردن(206 عام 2010 ) (جنار محسن حسن2017 : 16).
1. هناك تطور ملحوظ في إزدياد حالات الطلاق على مستوى المحافظة للفتزة المدروسة فن 404 حالة عام 2008 إزدادت الحالات لتصل في بموعها المى 7897 حالة، وسجل عام 2016 أكثر الحالات بواقع 1261 شكلت نسبة 16\% تقريبا من

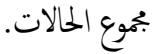
2. أكثر حالات الطلاق سجلت في قضاء دهوك بواق615 حالة وذلك في عام 2016 وشكلت هذه الحالات نسبة 17\% من بمحوع الحالات في القضاء للفترة المدروسة ونسبة 7.8\% من مجموع الحالات في المحافظة، ويلها على التوالي أقضية زاخو، نأكري،

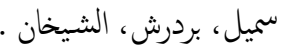
3. إستحواذ قضاءي دهوك وزاخو على نسبة أكثر من 71\% من بمجوع الحالات في المحافظة لفترة الدراسة وذلك بسبب الحجم السكاني الكبير للقضاءين وميل السكان الى كلى حل المشكلات العائلية عن طريق القانون ودور منظات الدفاع عن حقوق المرأة في 
الجدول(4) : معدل الطلاق الخام بالألف في محافظة دهوك (2008- 2016)

\begin{tabular}{|c|c|c|c|}
\hline & (الأعوام| & 2008 \\
\hline 0.35 & 404 & 1132581 & 2009 \\
\hline 0.48 & 569 & 1171231 & 2010 \\
\hline 0.54 & 659 & 1211053 & 2011 \\
\hline 0.56 & 712 & 1252229 & 2012 \\
\hline 0.70 & 914 & 1294804 & 2013 \\
\hline 0.78 & 1053 & 1336944 & 2014 \\
\hline 0.79 & 1103 & 1379675 & 2015 \\
\hline 0.86 & 1226 & 1423114 & 2016 \\
\hline 0.85 & 1261 & 1467198 & الألفاق \\
\hline
\end{tabular}

المصدر : عمل الباحثين بالاعتماد على الجدول(3) و حكومة اقليم كوردستان، وزارة التخطيط، هيئة احصاء الاقليم، مديرية احصاء محافظة دهوك، بيانات غير منشورة عن

إسقاطات السكان.

حادي الحديثي 2008 : 15): ومن ملاحظة الجدول(5) والشكل (3) نجد ان هناك

3. تركيب حالات الزواج والطلاق في محافظة دهوك 2016

تباين مكاني كير في عدد حالات الزواج وأيضا تباين حسب الفئات العرية وكالاتي :

3.1

ان تشجيع الزواج والخصوبة ظهر مبكرا من قيام الدولة العراقية نظرا لقلة عدد سكانه

ويبقى التدخل السياسي في الخصوبة يشكل محور معظم السياسات السكانية (طه الجدول (5) : التركب العمري لحالات الزواج في محافظة دهوك 2016

\begin{tabular}{|c|c|c|c|c|c|c|c|c|c|c|}
\hline المجموع & 60فاكثر & $55-50$ & $50-45$ & $45-40$ & $40-35$ & $35-30$ & $30-25$ & $25-20$ & $20-15$ & القضاء \\
\hline 3019 & 22 & 18 & 23 & 41 & 217 & 529 & 1273 & 803 & 83 & دهوك \\
\hline 1347 & 4 & 2 & 10 & 13 & 24 & 92 & 344 & 474 & 383 & ئكري \\
\hline 988 & & 10 & 4 & 40 & 103 & 136 & 210 & 318 & 163 & سميل \\
\hline 892 & 3 & 3 & 2 & 10 & 3 & 37 & 196 & 440 & 197 & بردرش \\
\hline 404 & & & 3 & 1 & 7 & 32 & 152 & 173 & 35 & الشيخان \\
\hline 557 & 1 & 1 & 3 & 4 & 21 & 91 & 211 & 145 & 79 & ئاميدي \\
\hline 2139 & 9 & 11 & 14 & 34 & 66 & 269 & 812 & 767 & 152 & زاخو \\
\hline 9346 & 39 & 45 & 59 & 143 & 441 & 1186 & 3198 & 3120 & 1092 & المجموع \\
\hline
\end{tabular}

المصدر : عمل الباحثين بالاعتماد على : حكومة اقليم كوردستان، وزارة العدل، رئاسة إستئناف منطقة دهوك، محكة الاحوال الشخصية في محافظة دهوك، بيانات غير منشورة. 1. أكبر عدد من حالات الزواج في المحافظة سجل في الفئة العمرية (25- 30) سنة تضيل الزواج في عمر مبكر ومراعاة العادات والتقاليد، مع ملاحظة عدم تسجيل أية وبواقع 3198 حالة وبنسبة 34.2\% وذلك لان هذا العمر يعتبر أنسب عمر للزواج حالة في الشيخان في الفئنين المذكورتين. 3. أما على مستوى الأقضة، فقد كانت دهوك أيضا في المركز الاول وذلك خصوصا بعد إكمال الدراسة والتخرج والحصول على وظيفة مناسبة . 2. أما أقل حالات الزواج على مستوى المحافظة، فقد كانت في الفئتين (50- بتسجيلها 3019 حالة زواج بنسبة 32.3\% على إعتبارها مركزا للمحافظة وتميز 55)و(55- 60 ) سنة وبواقع 84 حالة فقط بنسبة فقط 0.8\% وذلك بسبب بحجمها السكاني الكبير مقارنة بغيرها من مدن المحافظة. 


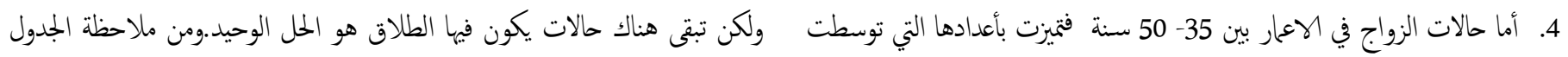
الأعهار التي تسبقها وكذلك الاعمار التي تليها وذلك بسبب حالة الاستقرار النفسي (6) والشكل(4) نجد ان الحالات المشار إليها توزعت على الفئات العمرية وبنسب

$$
\begin{aligned}
& \text { متباينة وكلاتي : } \\
& \text { والعاطفي الذي يتميز به الانسان في هذا العمر. }
\end{aligned}
$$

اما بالنسبة للطلاق ورغ أنه أبغض الحلال ولا يلجأ إليه إلا في الحالات المستعصية على الحل، وتتبع الحلول الاجتاعية لحل المشاكل بين الزوجين في أغلب الاحيان،

\begin{tabular}{|c|c|c|c|c|c|c|c|c|c|c|c|}
\hline المجموع & 60فاكثر & 60-55 & 55-50 & 50-45 & $45-40$ & $40-35$ & $35-30$ & $30-25$ & $25-20$ & $20-15$ & القضاء \\
\hline 615 & 9 & 11 & 5 & 22 & 48 & 82 & 153 & 146 & 95 & 44 & دهوك \\
\hline 99 & 0 & 0 & 0 & 0 & 1 & 4 & 15 & 27 & 28 & 24 & ناكري \\
\hline 105 & 0 & 0 & 4 & 4 & 12 & 18 & 32 & 27 & 8 & 0 & سميل \\
\hline 70 & 0 & 4 & 3 & 6 & 3 & 14 & 4 & 7 & 14 & 15 & بردرش \\
\hline 20 & 1 & 0 & 0 & 1 & 0 & 2 & 4 & 8 & 3 & 1 & الشيخان \\
\hline 30 & 0 & 0 & 0 & 2 & 1 & 4 & 7 & 8 & 5 & 2 & ئاميدي \\
\hline 323 & 0 & 0 & 0 & 9 & 19 & 50 & 49 & 74 & 66 & 55 & زاخو \\
\hline 1262 & 10 & 15 & 12 & 44 & 84 & 174 & 264 & 297 & 219 & 141 & المجموع \\
\hline
\end{tabular}
الجدول (6) : التزكيب العمري لحالات الطلاق في محافظة دهوك 2016

المصدر : عمل الباحثين بالاعتماد على : حكومة اقليم كوردستان، وزارة العدل، رئاسة إستئناف منطقة دهوك، محكة الاحوال الشخصية في محفظة دهوك، بيانات غير منشورة 1. كان نصيب الفئة العمرية (25- 30) سنة الأكبر من بين الفئات العمرية الاخرى، 3. وعلى مستوى الاقضية فقد جاء قضاء دهوك في المرتبة الاولى للفئة العمرية (35-30) سنة، فقد سبلت 153 حالة شكلت نسبة 24.8\% على مستوى القضاء حيث سجلت 297 حالة طلاق على مستوى المحافظة شكلت نسبة 23.5\% وهي نفسا الفئة الاكبر من حيث حالات الزواج، ويرجع السبب الى إرتفاع نسبة البطالة وذلك بسبب عدم وجود التفاهم بين الزوجين في السنوات الأولى من الزواج بسبب وعدم تعيين الخريين وتدني سوق العمل وإنخفاض رواتب الموظفين وهو ما يساعد إما عدم معرفنها لطباع بعضها البعض وهو ما يؤدي الى حدوث المشاكل وتدخل

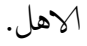

اما أقل الحالات فقد كانت في الشيخان، حيث لم تسجل إلا 20 حالات ساهمت بنسبة 1.6\%، وذلك بسبب صلات القربى بين أهالي المنطقة والتي تحول دون الوصول الى الطلاق حتى مع وجود المشاكل الزوجية والتي يصار الى حلها بالطرق الاجتاعية المعروفةبالاضافة الى سيادة التقاليد العشائرية التي تنبذ الطلاق. على ظهور وتفاق المشكلات الزوجية.

2. أما أقل الحالات فقد كانت في الفئة العمرية (60 سنة فأكثر) وبواقع 10حالات فقط شكت نسبة 0.7\%، وهذا يوضح وجود التفام والعشرة الحسنة بين الزوجين مع تقدم العمر يضاف الى ذلك مراعاة التقاليد الجنماعية والعشائرية التي تنبذ الطلاق

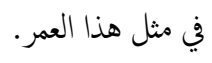


الشكل (3) : التزكيب العمري لحالات الزواج في محافظة دهوك 2016

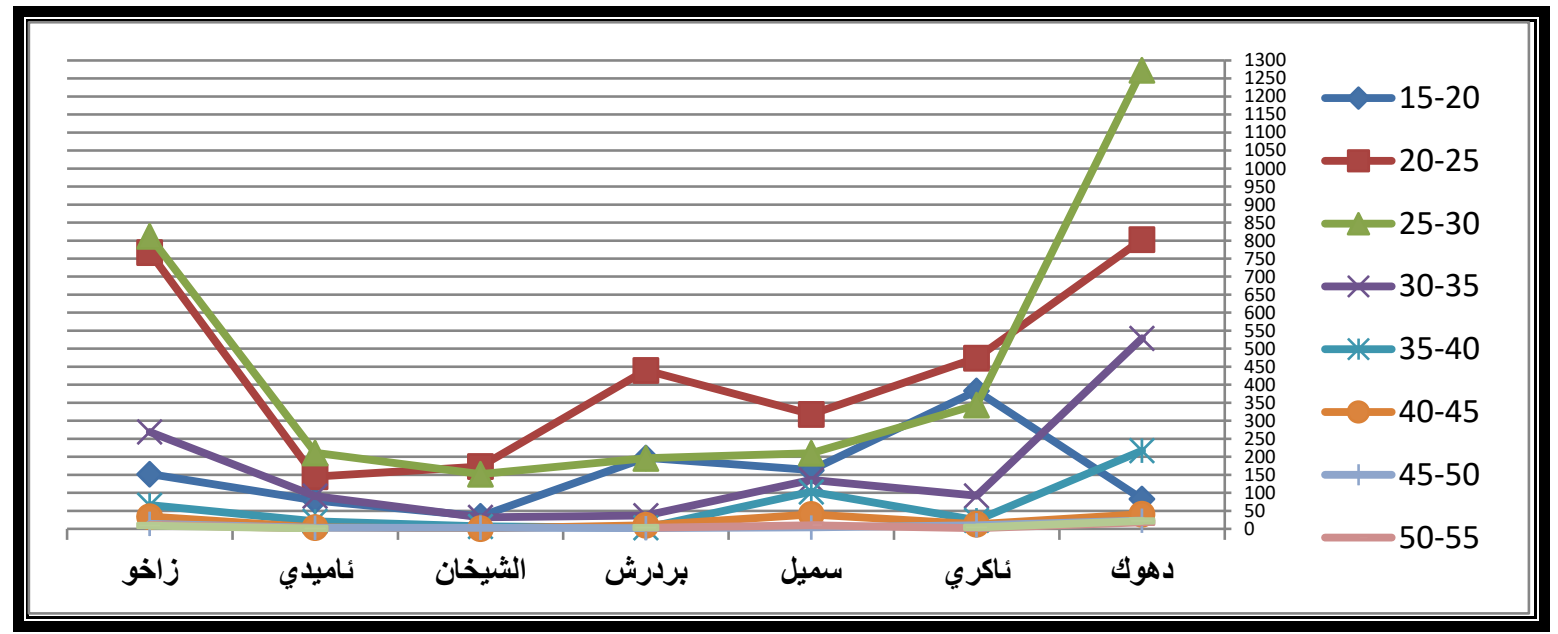

المصدر : من عمل الباحثين بالاعتماد على الجدول (5)

الشكل (4) : التزكيب العمري لحالات الطلاق في محافة دهوك 2016

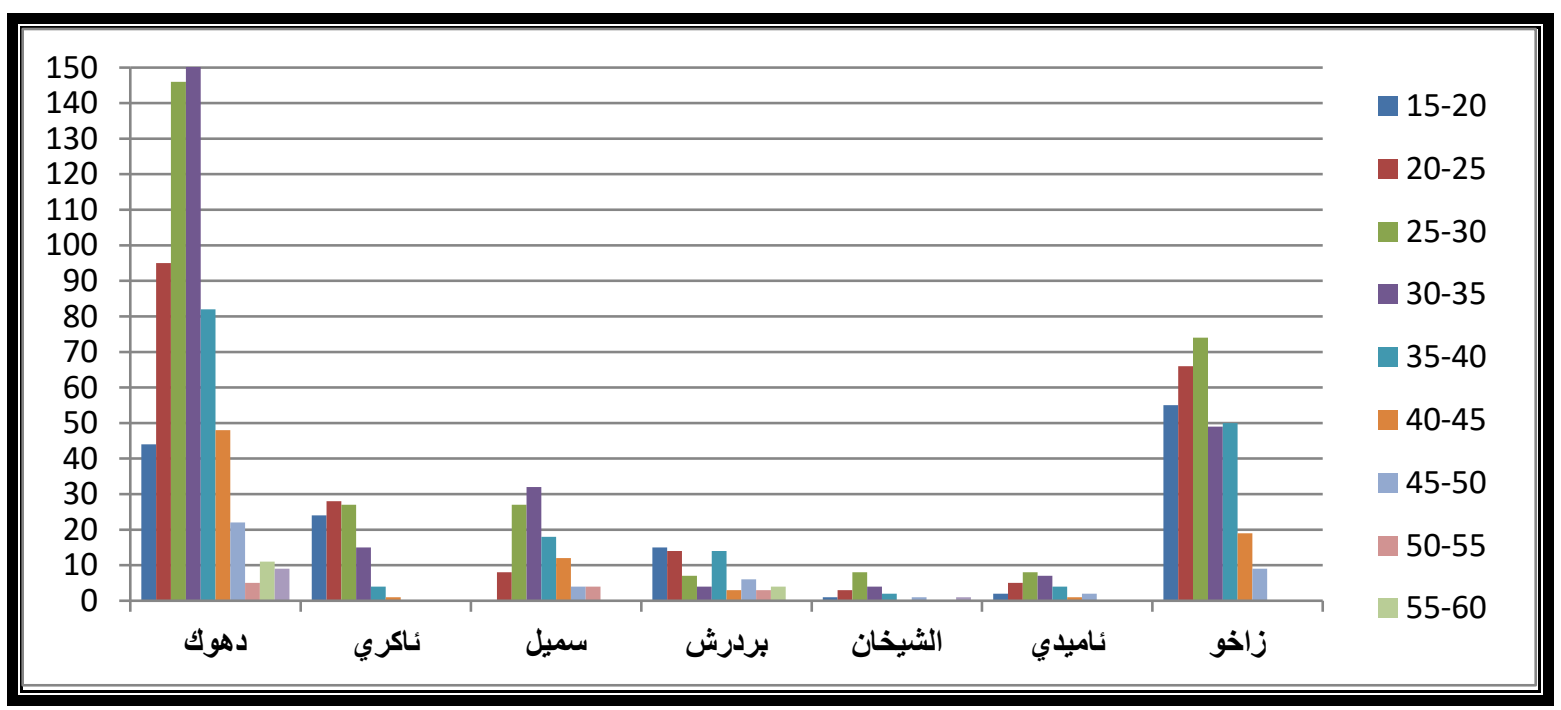

المصدر : عمل الباحثين بالاعتاد على : الجدول (6)

الانسان(مصطفى ابراهيم الزلي2001 : 16) .والجدول (7) يوضح هذا التزكيب ومنه

3.2

الزواج لغة : هو الضم أو الجمع، والوطء، والزواج الاقتران(وهبة الزحيلي 2008 : نلاحظ :

15) ويشترط في المرأة لاجل عقد الزواج شرطان الاول ان تكون أنثى محقة . س. سجلت اكثر حالات الزواج على مستوى المحافظة للذكور في الفئة العمرية (25الانوثة(وهبة الزحيلي 2008 : 61) والثاني ان لاتكون محرمة على الرجل كالبنت 30) بواقع 3198 حالة زواج بنسبة 34.2\% كون هذا العمر الأنسب للزواج من والاحت والعمة والخالة وبنات الأخ وبنات الأخت (احمد عيسى عاشور2006 : حيث الإستعداد من النواحي الاجتاعية والمالية. 369). إن الغرض الاساس من الزواج هو العفاف والنسل وبقاء سلالة 
في هذه الأعار مقارنة بالأعمار الأخرى التي تقل فيها المشاكل ويسود الإستقرار العلاقة الزوجية. 2. أكبر حالات الطلاق على مستوى المحافظة كانت في الفئة العمرية (25- 30) سنة للذكور بواقع 297 حالة شكلت نسبة 23.7\%، يقابلها أيضا 303 حالة طلاق للإناث في نفس الفئة العمرية وبنسبة 24.2\%وذلك لأسباب مالية وإجتاعية وغيرها. 3. أقل الحالات ظهرت في الفئة العمرية (60 سنة فأكثر)، حيث كان هناك 10 حالات للذكور بنسبة 0.7\% و حالة واحدة فقط للإناث بنسبة 0.07\%، حيث يسود العلاقة الزوجية الاستقرار والسكينة مع تقدم عمر الزوجين. 4. أما على مستوى الاقضية فقد سجل قضاء دهوك أعلى الحالات بواقع 615 حالة ساهمت بنسبة 48.7\% للنكور والإناث بسبب حجمها السكاني الكبير وتباين التركيب الاجتماعي لسكانها خصوصا مع وفود السكان من مناطق العراق الاخرى نتيجة للأحداث الامنية، وعلى عكس الحالة يقابلها أقل الحالات في قضاء الشيخان بواقع 20 حالة فقط وبنسبة 1.6\%. وعند مقارنة حالات الزواج والطلاق على مستوى المحافظة وحسب الاقضية لعام 2016 فتظهر لدينا الخارطة (1) والتي تبين إنخاض حالات الطلاق مقارنة مع حالات الزواج بشكل عام مع الإنتباه لزيادة حالات الطلاق وخصوصا في الاقضية ذات الحجم السكاني الكبير مثل دهوك وزاخو بالاضافة الى النسيج الاجتاعي المتباين من حيث الاتتاء المناطقي والعشائري وما يرتبط بذلك من العادات والتقاليد.

2. اما بالنسبة للإناث على مستوى المحافظة فقد سجلت أعلى حالات الزواج في الفئة العمرية (20- 25) سنة بواقع 3393 حالة زواج شكلت نسبة 36.3\%، فغالبا ما نكون الأثثى (الزوجة) في عمر أصغر من عمر الذكر ( الزوج). 3. أقل حالات الزواج كانت في الفئة العمرية (55- 60) سنة، حيث سجلت فقط 23 حالة لم تشكل سوى 0.2\% وبطبيعة الحال تقل حالات الزواج مع تقدم السن واغلب هذه الحالات كانت بسبب وفاة أحد الزوجين وخصوصا الزوجة أو بسبب

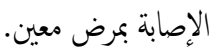
4. أما بالنسبة للإناث على مستوى محافظة دهوك فقد سجلت أدنى حالات الزواج في الفئة العمرية (65 سنة فاكثر) )وهي حالة واحدة فقط وبنسبة 0.01\%. 5. أما على مستوى الاقضية فقد جاء قضاء دهوك بالمرتبة الأولى وكان مجموع حالات الزواج هو 3019 حالة شكلت نسبة 32.3\% من مجموع حالات الزواج في المحافظة بسبب حجمها السكاني الكبير وكونها مركزا للمحافظة. شرع الزواج لتكوين الأسرة ودوام العشرة والمودة بين الزوجين، ولكن قد تصاب الحياة الزوجية بما لايستطاع معه العشرة وتصبح جحيا ويكون الطلاق هو الحل الوحيد(عثمان التكروري 2004 : 174)، فبالنسبة للتركيب النوعي لحالات الطلاق فالجدول (8) يوضح هذا التزكيب ومنه نلاحظ : 1. بصورة عامة تركزت حالات الطلاق في الفئات العمرية الحمس الأولى أي الهعار بين 15 - 40 سنة مقارنة بالفئات الاخرى، حيث تظهر معظم المشاكل الزوجية الجدول (7) : التركيب النوعي لحالات الزواج في محفظة دهوك 2016

\begin{tabular}{|c|c|c|c|c|c|c|c|c|c|c|c|c|c|c|c|c|c|c|c|c|c|c|}
\hline \multicolumn{2}{|c|}{ المجموع } & \multicolumn{2}{|c|}{ 60فاكثر } & \multicolumn{2}{|c|}{$60 \_55$} & \multicolumn{2}{|c|}{ 55_50 } & \multicolumn{2}{|c|}{$50 \_45$} & \multicolumn{2}{|c|}{$45 \_40$} & \multicolumn{2}{|c|}{$40 \_35$} & \multicolumn{2}{|c|}{ 35_30 } & \multicolumn{2}{|c|}{$30 \_25$} & \multicolumn{2}{|c|}{$25 \_20$} & \multicolumn{2}{|c|}{$20-15$} & \multirow[b]{2}{*}{ القضاء } \\
\hline إناث & ذوكر & $\begin{array}{l}\text { إنا } \\
\text { ث }\end{array}$ & ذكو & ثإن & ذوك & إنا & ذكو & $\begin{array}{l}\text { إنا } \\
\text { ث }\end{array}$ & ذوك & $\begin{array}{l}\text { إنا } \\
\text { ث }\end{array}$ & ذوك & $\begin{array}{l}\text { إنا } \\
\text { ث }\end{array}$ & ذوك & $\begin{array}{l}\text { إنا } \\
\end{array}$ & ذكور & إناث & ذكور & إناث & ذكور & إناث & ذكور & \\
\hline $\begin{array}{c}301 \\
9\end{array}$ & $\begin{array}{c}301 \\
9\end{array}$ & 0 & 22 & 2 & 10 & 4 & 18 & 13 & 23 & 48 & 41 & 73 & $\begin{array}{c}21 \\
7\end{array}$ & $\begin{array}{c}21 \\
4\end{array}$ & 529 & 735 & $\begin{array}{c}127 \\
3\end{array}$ & $\begin{array}{c}123 \\
7\end{array}$ & 803 & 693 & 83 & دهوك \\
\hline $\begin{array}{c}134 \\
7\end{array}$ & $\begin{array}{c}134 \\
7\end{array}$ & 0 & 4 & 0 & 1 & 0 & 2 & 1 & 10 & 4 & 13 & 6 & 24 & 38 & 92 & 271 & 344 & 453 & 474 & 574 & 383 & ئاكري \\
\hline 988 & 988 & 0 & 0 & 1 & 4 & 1 & 10 & 6 & 4 & 27 & 40 & 71 & $\begin{array}{c}10 \\
3\end{array}$ & 99 & 136 & 215 & 210 & 275 & 318 & 293 & 163 & سميل \\
\hline 892 & 892 & 0 & 3 & 0 & 1 & 1 & 3 & 0 & 2 & 5 & 10 & 4 & 3 & 18 & 37 & 76 & 196 & 239 & 440 & 549 & 197 & بردرش \\
\hline 404 & 404 & 0 & 0 & 0 & 1 & 0 & 0 & 0 & 3 & 1 & 1 & 5 & 7 & 11 & 32 & 62 & 152 & 177 & 173 & 148 & 35 & الشيخ \\
\hline 557 & 557 & 0 & 1 & 0 & 1 & 0 & 1 & 1 & 3 & 7 & 4 & 13 & 21 & 50 & 91 & 132 & 211 & 186 & 145 & 168 & 79 & ئاميد \\
\hline
\end{tabular}




\begin{tabular}{|c|c|c|c|c|c|c|c|c|c|c|c|c|c|c|c|c|c|c|c|c|c|c|}
\hline $\begin{array}{c}213 \\
9\end{array}$ & $\begin{array}{c}213 \\
9\end{array}$ & 1 & 9 & 1 & 5 & 3 & 11 & 3 & 14 & 14 & 34 & 32 & 66 & $\begin{array}{c}10 \\
2\end{array}$ & 269 & 409 & 812 & 826 & 767 & 745 & 152 & 9 \\
\hline $\begin{array}{c}934 \\
6\end{array}$ & $\begin{array}{c}934 \\
6\end{array}$ & 1 & 39 & 4 & 23 & 9 & 45 & 24 & 59 & $\begin{array}{c}17 \\
6\end{array}$ & $\begin{array}{c}14 \\
3\end{array}$ & $\begin{array}{c}20 \\
4\end{array}$ & $\begin{array}{c}44 \\
1\end{array}$ & $\begin{array}{c}53 \\
2\end{array}$ & $\begin{array}{c}118 \\
6\end{array}$ & $\begin{array}{c}190 \\
0\end{array}$ & $\begin{array}{c}319 \\
8\end{array}$ & $\begin{array}{c}339 \\
3\end{array}$ & $\begin{array}{c}312 \\
0\end{array}$ & $\begin{array}{c}317 \\
0\end{array}$ & $\begin{array}{c}109 \\
2\end{array}$ & \begin{tabular}{l} 
gar \\
\hline
\end{tabular} \\
\hline
\end{tabular}

المصدر : عمل الباحثين بالاعتماد على : حكومة اقليم وكردستان، وزارة العدل، رئاسة إستئناف منطقة دهوك، محكة الاحوال الشخصية في محفظة دهوك، بيانات غير منشورة. الجدول (8) : التركيب النوعي لحالات الطلاق في محفظة دهوك 2016

\begin{tabular}{|c|c|c|c|c|c|c|c|c|c|c|c|c|c|c|c|c|c|c|c|c|c|c|}
\hline \multicolumn{2}{|c|}{ الجمموع } & \multicolumn{2}{|c|}{ 606كاكثر } & \multicolumn{2}{|c|}{$60 \_55$} & \multicolumn{2}{|c|}{ 55_50 } & \multicolumn{2}{|c|}{$50 \_45$} & \multicolumn{2}{|c|}{$45 \_40$} & \multicolumn{2}{|c|}{$40 \_35$} & \multicolumn{2}{|c|}{ 35_30 } & \multicolumn{2}{|c|}{ 30_25 } & \multicolumn{2}{|c|}{ 25_20 } & \multicolumn{2}{|c|}{ 20_15 } & \multirow[b]{2}{*}{ القضاء } \\
\hline إناث & ذكور & $\begin{array}{l}\text { إنا } \\
\text { ث }\end{array}$ & ذوك & $\begin{array}{l}\text { إنا } \\
\text { ث }\end{array}$ & ذوك & $\begin{array}{l}\text { إنا } \\
\text { ثا }\end{array}$ & ذك & $\begin{array}{l}\text { إنا } \\
\end{array}$ & ذك & $\begin{array}{l}\text { إنا } \\
\end{array}$ & ذك & إنا & ذذو & $\begin{array}{l}\text { إنا } \\
\end{array}$ & ذوك & $\begin{array}{l}\text { إنا } \\
\end{array}$ & ذذو & $\begin{array}{l}\text { إنا } \\
\end{array}$ & ذو ر & إنا & ذو ر & \\
\hline 615 & 615 & 1 & 9 & 2 & 11 & 8 & 5 & 4 & 22 & 46 & 48 & 70 & 82 & $\begin{array}{c}12 \\
4\end{array}$ & $\begin{array}{c}15 \\
3\end{array}$ & 6 & $\begin{array}{c}14 \\
6\end{array}$ & $\begin{array}{c}14 \\
9\end{array}$ & 95 & 45 & 44 & دهوك \\
\hline 99 & 99 & 0 & 0 & 0 & 0 & 0 & 0 & 0 & 0 & 0 & 1 & 4 & 4 & 8 & 15 & 30 & 27 & 38 & 28 & 19 & 24 & ئآري \\
\hline 105 & 105 & 0 & 0 & 0 & 0 & 1 & 4 & 4 & 4 & 7 & 12 & 15 & 18 & 34 & 32 & 28 & 27 & 16 & 8 & 0 & 0 & سميل \\
\hline 70 & 70 & 0 & 0 & 9 & 4 & 0 & 3 & $J$ & 6 & 4 & 3 & 13 & 14 & $J$ & 4 & 8 & 7 & 14 & 14 & 14 & 15 & بردرش \\
\hline 20 & 20 & 0 & 1 & 0 & 0 & 0 & 0 & 0 & 1 & 2 & 0 & 1 & 2 & 7 & 4 & 3 & 8 & 3 & 3 & 4 & 1 & الشيخان \\
\hline 30 & 30 & 0 & 0 & 0 & 0 & 0 & 1 & 1 & 2 & 3 & 1 & 1 & 4 & 2 & 7 & 10 & 8 & 8 & 5 & 5 & 2 & ئاميدي \\
\hline 232 & 232 & 0 & 0 & 0 & 0 & 0 & 0 & 14 & 9 & 19 & 19 & 45 & 50 & 54 & 49 & 58 & 74 & 71 & 66 & 61 & 55 & زاخو \\
\hline $\begin{array}{c}126 \\
1\end{array}$ & $\begin{array}{c}126 \\
1\end{array}$ & 1 & 10 & 11 & 15 & 9 & 13 & 28 & 44 & 81 & 84 & $\begin{array}{c}14 \\
9\end{array}$ & $\begin{array}{c}17 \\
4\end{array}$ & $\begin{array}{c}23 \\
2\end{array}$ & $\begin{array}{c}26 \\
4\end{array}$ & $\begin{array}{c}30 \\
3\end{array}$ & $\begin{array}{c}29 \\
7\end{array}$ & $\begin{array}{c}29 \\
9\end{array}$ & $\begin{array}{c}21 \\
9\end{array}$ & $\begin{array}{c}14 \\
8\end{array}$ & $\begin{array}{c}14 \\
1\end{array}$ & 9 \\
\hline
\end{tabular}

المصدر : عمل الباحثين بالاعتمد على : حكومة اقليم كوردستان، وزارة العدل، رئاسة إستئناف منطقة دهوك، محكة الاحوال الشخصية في محفظة دهوك، بيانات غير منشورة. الخارطة (1) : التباين المكاني للزواج والطلاق في محافظة دهوك عام 2016

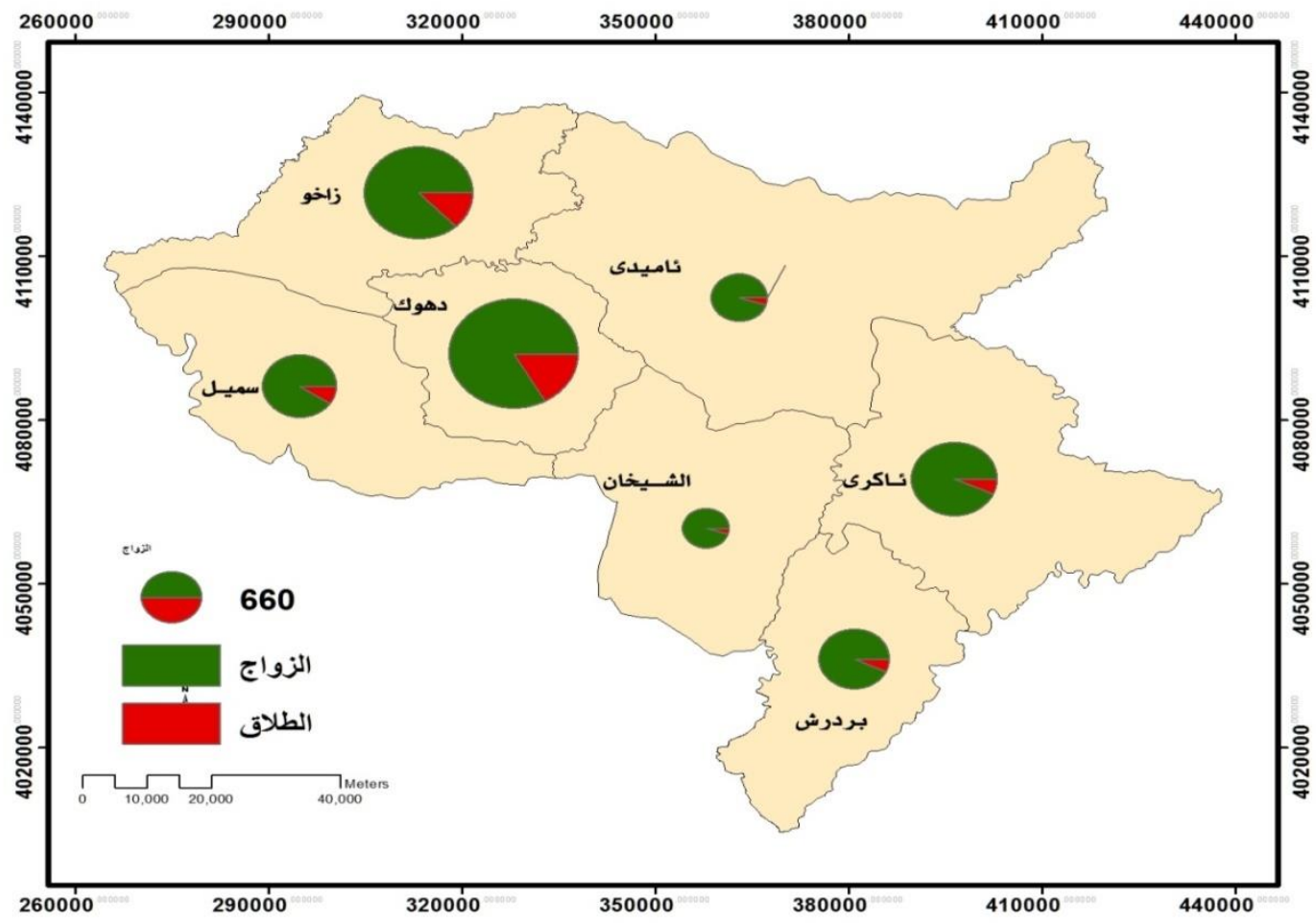

المصدر : عمل الباحثين بالاعتاد على الجدولين ( 7) و (8) وخارطة محافظة دهوك. 
الاخرى من مدينة الى اخرى ومن منطقة الى منطقة ثانية، وهنا سيتم البحث في اهم

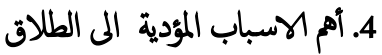

إن تباين حالات الطلاق زمانيا ومكانيا يعود الى مسببات وعوامل عدة تتباين هي تلك الاسباب وكالاتي، أنظر الجدول (9). الجدول (9) : أسباب الطلاق في محافظة دهوك 2016

\begin{tabular}{|c|c|c|c|c|c|c|c|c|c|c|c|c|c|c|c|c|}
\hline$\%$ & المجموع & $\%$ & ن الشيخا & $\%$ & بردرش & $\%$ & سميل & $\%$ & ئاميد & $\%$ & زاخو & $\%$ & تَكري & $\%$ & دهو & $\begin{array}{r}\text { العوامل } \\
\text { الع }\end{array}$ \\
\hline 71.4 & 902 & 90 & 18 & 64.2 & 45 & 61.9 & 65 & 50 & 15 & $\begin{array}{r}61 . \\
9\end{array}$ & 200 & $\begin{array}{r}72 . \\
7\end{array}$ & 72 & 79.2 & 487 & 1 \\
\hline 3.3 & 42 & & & 4.3 & 3 & & & 16.7 & 5 & 3.4 & 11 & 3.3 & 3 & 3.3 & 20 & 2 \\
\hline 0.7 & 9 & & & & & & & 6.7 & 2 & & - & & - & 1.1 & 7 & 3 \\
\hline 2.2 & 27 & & & & & 4.8 & 5 & & & 1 & 3 & 3 & 3 & 2.6 & 16 & 4 \\
\hline 2 & 25 & & & 1.4 & 1 & 16.2 & 17 & & & 1.2 & 4 & & - & 0.5 & 3 & 5 \\
\hline 1.1 & 14 & & & 2.9 & 2 & 0.95 & 1 & 3.3 & 1 & 2.8 & 9 & & - & 0.16 & 1 & 6 \\
\hline 2.5 & 31 & & & 10 & 7 & 4.8 & 5 & 3.3 & 1 & 1.9 & 6 & 5 & 5 & 1.1 & 7 & 7 \\
\hline 9.4 & 118 & 10 & 2 & 17.2 & 12 & 0.95 & 1 & & & $\begin{array}{r}25 . \\
4\end{array}$ & 82 & 4 & 4 & 2.8 & 17 & 8 \\
\hline 3.4 & 43 & & & & & & & & & & - & & - & 7 & 43 & 9 \\
\hline 4 & 51 & & & & & 10.5 & 11 & 20 & 6 & 2.4 & 8 & 12 & 12 & 2.3 & 14 & 10 \\
\hline 100 & 1262 & 100 & 20 & 100 & 70 & 100 & 105 & 100 & 30 & 100 & 323 & 100 & 99 & 100 & 615 & الجمجمو9 \\
\hline
\end{tabular}

الأرقام تشير الى ترتيب العوامل حسب ورودها في المتن.

المصدر : عمل الباحثين بالاعتماد على : حكومة اقليم كوردستان، وزارة العدل، رئاسة إستئناف منطقة دهوك، محكمة الاحوال الشخصية في محافظة دهوك ب بيانات غير منشورة.

1. عدم التوافق بين الزوجين الزواج كأي مشروع جديد تنقصه الخبرات وتصقله عادة ينتقر الى النضج الاجتاعي بسبب الظروف الاقتصادية والاجتاعية وتدني الايام والتجارب واذا لم يفهم كل من الزوجين طبيعة شخصية الاخر ويتعاملا مع المستوى الثقافي والوازع الديني لدى المتزوجين مبكرا، وقد لاحظنا إستنادا الى بعضها بالعقل والحكمة والطريقة المناسبة سوف ينهيان المى الطلاق، لذا نجد ان الاحصائيات ان الكثير من المتزوجين خاصة الزوجة لاتتجاوز عمرها خمة عشر عاما الخلافات الزوجية تبدأ بالظهور منذ الأشهر الأولى للزواج وإستحالة حصول الوئام وهذا يعني إفنقار الزوجين الى فكرة واضحة عن الزواج وواجباته والمسؤولية الأسرية والمجبة بينها بسبب صعوبة التوافق بنهها سواء كان التوافق الفكري وتوافق في والاعتاد على الاهل في حل مشكلاتهم كشكلة السكن والمعيشة والسلوك وطريقة الشخصية والطباع والانسجام الروحي والعاطني فيبدأكل طرف يكيل التهم للطرف التفكير وغير ذلك مما يفسح المجال واسعا لندخل الاهل من الطرفين في حياتها

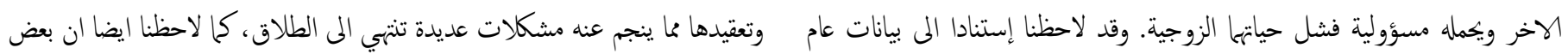
2016 لحالات الزواج والطلاق لدى المحكة الشرعية ان هذا العامل او السبب قد العوائل ترغز بناتها على الزواج من شخص يكبرهن سنا لدوافع اقتصادية او اجتماعية او غير ذلك دون ان يعلموا عواقب هذا الوزاج، وقد لاجظنا استنادا الى بيانات عام 2016 ان هذا العامل كان تأثيره بنسبة 3.3\% في حصول حالات الطلاق وسبلت ساهم بنسب كبرة في جميع الاقضية ليأتي في المرتبة الأولى بواقع 902 حالة توزعت في جميع الاقضية وبنسبة 71.4\% من جملة الاسباب المؤدية الى الطلاق . 42 حالة طلاق بسبب هذا العامل في معظم الاقضية. 3. العقم أو إصابة أحد الزوجين بالمرض إذا كان الطلاق شرعه الله لعلاج الحلات المستعصية التي لايمكن فها الصلاح بين الزوجين ويتعذر معه دوام الحياة الزوجية 2. الزواج المبكر وتفاوت العمر بين الزوجين إذا كان الزواج المبكر هو إستجابة لمرحلة البلوغ الجنسي لدى الانسان الذي يبدأ مبكرا لدى الشباب والشابات وخوف العوائل من وقوع ابنائها في المخظور الشرعي والاجتمي إلا أن هذا النوع من الزواج 
العامل السبب في حدوث 25 حالة وبنسبة 2\% فقط وذلك في اقضية دهوك وزاخو

وسميل وبردرش.

6. وسائل الإعلام والتطور التكنولوجي تشكل وسائل الإعلام بكل فروعه المرئية والألكترونية والمكتوبة من اهم ادوات النظام الرأسمالي العالمي في معركها الاقتصادية والثقافية بحيث أصبحنا اليوم أمام ثقافة مرجعيتها السوق والربح وفق مصاح هذا النظام بدلا من خصوصيتنا الوطنية والقومية وإنتائنا الديني والاجتاعي والسياسي وباتت ثقافتنا الوطنية والقومية تتعرض للنهديد بنعل التعميم القسري للقيم الغربية بإستخدام وسائل الغعلام حتى أصبحنا اليوم مقلدين لتلك الثقافة ومجرورين ورائها من الألف المى الياء، فالحياة الزوجية الرومانسية التي يتخيلها الثاب أو الفناة عبر ما تبثه الفضائيات والانتزيت سرعان ما تصطدم بالواقع الاجتاعي وأعباء الحياة وتتبدد بسرعة كل تلك الإحلام والامال وتسود المشاكل العائلية وتسمم العلاقات الزوجية حتى يختار الزوجان الحل الأسرع وهو الطلاق. وكان لهذا العامل تأثير بنسبة قليلة بلغت 1.1\% وذلك في أقضية دهوك وزاخو وئاميدي وسميل وبردرش. 7. اسباب اجتاعية وتدخل الاهل والاقارب بين الزوجين وهذه الاسباب لاتنفصل في بمحلها عن الاسباب التي ذكرناها فيا تقدم ومنها عدم الثقة بالنفس أو بالطرف الثاني من الزواج بسبب التربية العائلية الخاطئة أو النفكك الأسري او النظر الى الزواج على انه صفقة تجارية الكل فيها يريد ان يربح ولا أحد يقبل بالحسارة أو التضحية من اجل دوام الحياة الزوجية وسعادتها، فالمهور العالية وتكاليف تههيز الدار الزوجية والمغالاة في طلب الذهب وتكاليف حفلة الزواج كل ذلك يؤدي الى إرهاق الزوج بأعباء مالية تفوق غمكانياته وقد يضطر الى الإستدانة أحيانا كثيرة الأمر الذي يجعل النفوس متوترة قالحياة الزوجية مشوبة بعدم الإستقرار ويكيل كل طرف التهم على الطرف الاخر وتكثر الأقاويل والقصص المفبركة والطعن في الكرامة وأحيانا يضطر الزوج الى بيع المصوغات الذهبية لزوجته عنوة وقسم من أثاث البيت لسداد ديون الزواج منها فتصبح سباا للخلافات الزوجية وعدم الإنسجام وتدخل الأهل بينها فيكون أبغض الحلال طريقا لحلها لذا حري بالأباء والأهات الإلنزام بقواعد الدين الاسلاي في إختيار من يصلح زوجا لإبنته. ومن خلال ملاحظة الجدول (7) نجد أن هذا العامل قد تسبب في حدوث31 حالة بنسبة 2.5\% وسبلت هذه الحالات في جميع الاقضية وباعداد متقاربة ماعدا قضاء الشيخان.
ويكون فراقها خير من غنتمها مثل عقم الزوجة او الزوج او إصابة احدها بالمرض المزمن الثابت المانع من المعاشرة الزوجية والذي لايرجى الشفاء منه لذا قبل الزواج يجب إجراء الفحوصات والتحاليل الطبية بحيث يتم الالتثبيت من سلامة الزوجين من الامراض السارية والموانع الصحية وقد تسبب هذا العامل قد تسبب في حدوث 9 حالات من الطلاق كانت في دهوك وئاميدي وشكلت نسبة 0.7\% فقط لياتيت بالمرتبة الاخيرة من بين العوامل والاسباب.

4. الخيانة الزوجية المعروف ان التقاليد الاجتاعية السلمة في مجتمعنا الكوردي والتعاليم الدينية قد إستقرت على إعتبار الزواج النظام الاخلاقي والاجتاعي الوحيد المعترف به في تنظيم العلاقة الجنسية بين الرجل والمرأة وأن أية علاقة خارج إطار الزواج يعتبر فشاّ ورذيلة، والزواج قد لايخظى بالنجاح بسبب الاختيار الخاطيء والتقدير الغير سليم لشريك الحياة أو قد يحدث لما بعد الزواج أمر خارج إرادتها فيشوب حياتها الخلاف والشقاق ويتحول الحب والمودة البغض والرحمة الى الإنتقام والسكينة الى الفوضى وقد يستفحل الأمر كثيرا فيؤدي بها الى أو بأحدها الى إنراف أخلاقي أو سلوك إجراي تعرض حياتها للخطر وكزامتها للمهانة، وقد كان لهذا العامل دور في حدوث الطلاق بنسبة 2.2\% وبواقع 27 حالة توزعت بين أقضية دهوك وئكري وزاخو وسميل. 5. الهجرة وتزوج الزوج للمرة الثانية شهدت السنوات التي سبقت إنهيار النظام الدكتاتوري نزوح أعداد كيرة من سكان الأقليم المى الخارج على خلفية غنتفاضة شعبنا الكوردي عام 1991 وتطبيق سياسة الحصار الاقتصادي ضده فيا بعد من قبل النظام وتفشي ظاهرة البطالة والتطبيقات الامنية المنعسفة التي مورست بحقه فأضطر الكثير منهم الى ترك زوجاتهم وعوائهم خلفهم أملا بسحبه لاحقا بعد الإستقرار في تلك الدول والحصول على حق اللجوء الإنساني او السياسي فها، إلا أن البعض من هؤلاءتعذر عليه الحصول على موافقة تاك الدول على لم شمل عوائلهم، والبعض الاخر تزوجوا هناك من زوجة أخرى وتناسوا ان لهم زوجة وعائلة واطفال في إنظارهم وبتأثير الثقافة الغربية لم تعد الحياة الزوجية لدى البعض بالقدسية التي عليها في مجتمنا، كل ذلك دفع بعض الزوجات الى مراجعة المحاكُ الشرعية وإقامة دعاوى التفريق على أزواجهم مستفيدين من أحكام المادة 43/ والفقرة 2 من قانون الأحوال الشخصية التي تعطي الحق للزوجة في طلب التفريق من زوبحا غذا هرها مدة سنتين فأكثر بلا عذر مشروع إن كان الزوج معروف الإقامة وله مال يستطيع الإنفاق منه.وقد كان هذا 
10. أسباب أخرى للطلاق وهي اسباب ثانوية، لاتنفصل عن الأسباب الانقة الذكر لابل نتيجة طبيعية لها، ونذك منها الهواتف النقالة (الموبايل)، وماضي الزوجة وعلاقاتها العاطفية قبل الزواج والإختلاف في مستوى التعليم بين الزوجين وعدم النكفؤ الاجتاعي وإهال الزوجة لواجباتها داخل البيت وإختلاف العادات والتقاليد بين عائلة الزوجين وغيرها، وساهت هذه الاسباب بنسبة 4\% من حالات الطلاق وبواقع 51 حالة توزعت في اقضية دهوكك وزاخو وئكري وسميل ووئميدي .

الإستنتاجات

1. هناك تباين زماني واضح في حالات الزواج خلال الفترة (2008 - 2016) وهذا التباين يرجع الى التباين في الظروف السياسية والاجتاعية والاقتصادية وشمل التباين جميع المدن والأقضية التابعة لمحافظة دهوك، فني عام 2008 كانت نسبة الزواج في دهوك 34.7\% وإرتغت الى 36.4\% لتنخفض الى 30.5\% و 32.3\% في عامي

$$
2014 \text { و } 2016 \text { على التوالي. }
$$

2. هناك تباين مكاني واضح لحالات الزواج في المحافظة وبين منطقة واخرى وهو يرجع الى الإختلاف قي الظروف المعيشية والاجتاعية، فني زاخو بلغت21.7\% وفي سميل 7.18\% وفي قسروك 1.16\%. 3. يوجد تباين مكاني وزماني كير في حالات الطلاق خلال فترة الدراسة، وهذا التباين يرجع الى الظروف المعيشية وصعوبة الحياة والحرب ضد الإرهاب وإنخفاض رواتب موظني الدولة والبطالة وتدني سوق العمل، حيث كانت نسبة الطلاق في دهوك 43.06\% في عام 2008 في دهوك وإنخفضت الى 39.4\% في 2009 لترتغ مرة اخرى الى47.8\% عام 2016. أما بالنسبة الى التباين المكاني فهناك اختلاف بين

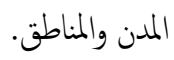
4. هناك تباين كبير في واقع حالات الزواج حسب التزكيب العمري والنوعي لسنة 2016 حيث ترتفع نسب الزواج في الفئات العمرية الصغيرة وتقل مع تقدم العمر. 5. أما بالنسبة للطلاق فقد كانت نسبه مرتفعة لدى الذكور والإناث على التوالي في الفئات العمرية الصغيرة وتقل هذه النسبة مع تقدم العمر. 6. هناك عدة أسباب تؤدي المى الطلاق منها عدم التوافق بين الزوجين، فرق العمر بينها، العقم وإصابة احدها بالامراض، الهجرة أو زواج الرجل بإمراة اخرى، بالاضافة

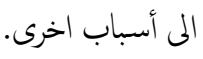

8. اسباب اقتصادية وعدم توفر الوحدة السكنية إن إنتشار ظاهرة البطالة وتكليف الزواج المرتفعة وغلاء المهور وعدم قدرة الزوج على تهيئة سكن ملائم لزوجته وتلبية متطلبات المعيشة لعائلته والتغير الكيبر على الرواتب كان من أبرز أسباب الطلاق كما ان المتغيرات الاقتصادية التي يشهدها أقليم كوردستان وبروز الطبقة البرجوازية وتنايي قدراتها بعد سقوط النظام السابق جعلت من المجميع يجيا في ظل أفكار ومفاهيم النظام الرأسمالي وإقتصاد السوق القائم على إستغلال الإنسان وإفساده وزرع عقلية إستهلاكية لدى الرجل والمرأة معا بحيث أصبح هم الزوجة والزوج هو المال والهو والإسراف والقصور والفلل والسيارات الفارهة واخر عمليات التجميل ناهيك عن إضعاف الوازع الديني والقيم الاجتاعية النبيلة في مجتمعاتنا، حتى أصبح الطلاق لدى الكثير من الناس حالة اجتاعية مقبولة بعد أن كانت وصمة عار على من يقوم عليها ويكننا القول وبكل أمانة ان لهذا العامل تأثير كير في حدوث الطلاق وجاء بالمرتبة الثانية بعد عامل (عدم التوافق بين الزوجين) وساهم بنسبة 9.4\% من حالات الطلاق في عام 2016 وسبل في جميع الاقضية ماعدا قضاء ناميدي وكان أكثرها في زاخوومن ثم في قضاء دهوك وبردرش ومن ثم بقية الاقضية . 9. تدني المستوى الثقافي وضعف الوازع الديني لاشك ان الزواج يترتب عله حقوق وواجبات لكل من الزوجين وعليها الإلتزام بها وإن الإخلال بالمسؤولية من أي طرف حتما سيكون السبب في زوال المودة والرمة التي إرتضاها الخالق للحياة الزوجية فتفقد الأسرة مقومات السعادةو والاستقرار وتصبح الحياة الزوجية لاتطاق وقد يدف بها الى طريق الطلاق. إن الندني في مستوى الوعي بالجقوق والواجبات الزوجية وإفتقار الزوجين لاسيا الجدد المى فكرة واضحة عن الزواج وواجباته والمسؤولية الأسرية يؤدي الى الطلاق. وقد لاحظنا إستنادا المى إحصائية عام 2016 المى ان هذا العامل كان السبب في حدوث 3.4\% من حالات الطلاق وبواقع 43 حالة سجلت جميعها في قضاء دهوك، لذا من الأفضل فتح مراكز للبحث الاجتماعي ورفدها بالكفاءات المختصة بماكل الأسرة مهمها تأهيل الزوجين وتقديم الإستشارات لمم عند الحاجة وتنبي وسائل الغعلام المختلفة للقضايا التي تخص الأسرة عامة والزواج خاصة ومساهمة علماء الدين في نشر التوعية الدينية بحسن المعاشرة بين الزوجين وبيان الحقوق والواجبات الزوجية بعقل متنور ومعاصر، واخيرا على الأباء والأهمات إعطاء فسحة من الزمن لفترة الخطوبة وتمكين الحطيبين من التعرف على بعضها جيدا قبل الزواج. 


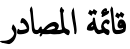

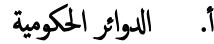

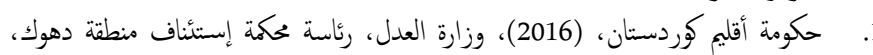

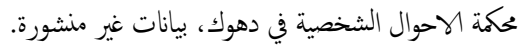
حكومة أقليم كوردستان، وزارة التخطيط، هيئة إحصاء الاقليم، مديرية إحصاء دهوك، ئاك،

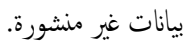

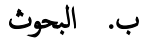

1. جنار مسن حسن، واقع الزواج والطلاق في محافظة دهوك حسب الاقضية للفترة(2008-

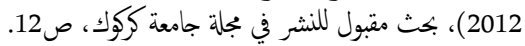

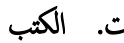

1. هناء ححسن العكيلي، (1989)، السياسات السكانية والمرأة العربية، الأم المتحدة، الأسكوا،

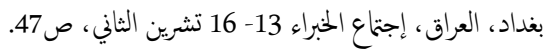

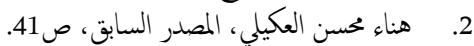

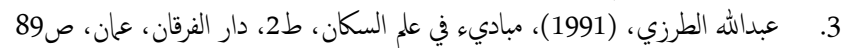

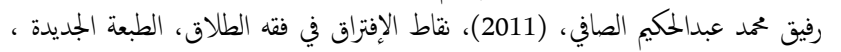
بيروت، لبنان، ص27. أميرة حسن الرافي، أحكام إيقاع الطلاق وأثارها، المكتب الفني، الهسكندرية، بدون سنة

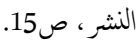
أحد علي الخطيب، (1980)، محمد عبيد الكبيسي، محمد عباس السامرائي، شرح قانون

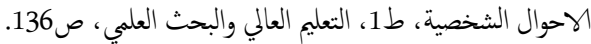

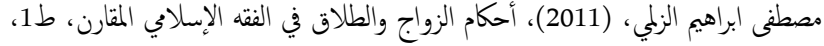

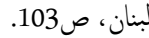
طه حادي الحديثي، جغرافية السكان، مديرية دار الكتب لطباعة والنشر، جامعة الموصل،

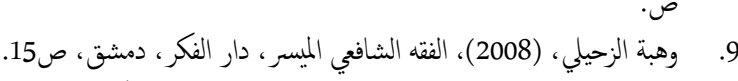

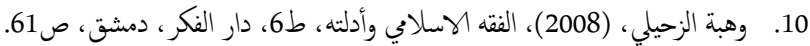

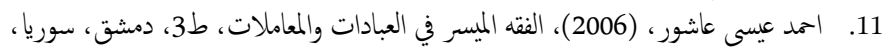

ص369. 12. مصطنى ابراهيم الزلي، (2011)، احكام الزواج والطلاق في الفقه الاسلاي المقارن، مصدر

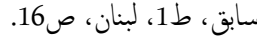
13. عثمان التكروري، (2004)، شرح قانون الاحوال الشخصية، ط1، عان، الاردن،

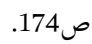

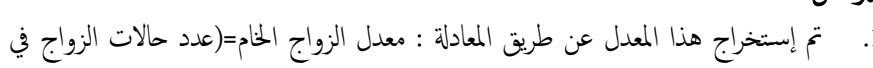

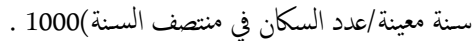

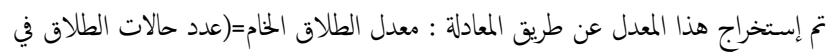

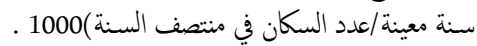

1. معالجة ظاهرة البطالة بين المتزوجين وتقديم سلف الزواج ومعونات مالية بدون فوائد لمن هم في بداية مشوار حياتهم الزوجية، فضعف المستوى الاقتصادي في الأسرة يعد سبا محا من أسباب الطلاق.

2. معالجة مشكلة السكن للمتزوجين من خلال بناء جمعات سكنية وتمليكها لم بأسعار رمزية او بأقساط شهرية تتناسب ودخلهم الشهري وكذلك توزيع أراضي سكنية عليه وتزويدهم بالمواد الغنشائية وتسهيل مهمة الأقراض من المصرف العقاري. 3. فتح مراكز للبحث الاجتماعي همتها عرض المشكلات الأسرية ( الزواج الطلاق - الططال- المهور) وتاهيل المتزوجين وتبني برامج نوعية من قبلها كإلقاء المحاضرات من قبل مختصين عن الحياة الزوجية وإقناعهم بالتخلي عن بعض العادات السلبية كالمطالبة بالمهور العالية والضغط على بناته وتزويجهن قسرا وترك حرية الاختيار لهن الى جانب تثقيف المتزوجين بمؤولياتهم وحقوقهم وبذل المساعي لإصلاح ذات البين في حالة حصول خلافات زوجية كما يجب رفد هذه المراكز بالمختصين بقضايا المجتع من أطباء ورجال قانون ودين وأسانذة علم النفس وتقديم بحوث ودراسات ميدانية حولأثار الطلاق وأسبابه وكيفية معالجته والتعرف على خصائص الفئات التي يكثر فيها الطلاق. 4. نشر الثقافة الدينية بين الناس لتقوية الوازع الديني لدى الزوجين وتكليف الحكومة لحطباء المساجد للمساهة في نشر التوعية الدينية بحسن المعانرة بين الزوجين وبيان الحقوق والواجبات الزوجية طبقا للشرائع السموية. 5. على محاً؟ الاحوال الشخصية عدم الإسراع في حسم دعاوى الطلاق قبل إسداء النصح والإرثاد لمم وتبصير مبعواقب الطلاق وإحالة الزوجين على الخبراء ومراكز البحث الاجتمي والتعرف على أسباب النزاع وتقديم العون لم. 6. تبني وسائل الهلام سيا المرئي منه للقضايا التي تخص الأسرة عامة والمرأة خاصة وإفراد مساحات واسعة لمعالجة قضاياها وتقديم برامج عن مشكلات الزواج والطلاق ونشر الوعي الاجتاعي والديني والقانوني بين الناس. 7. تقرير مفردة في مناجج الدراسة الاعدادية والجامعية عن مشاكل الأسرة والزواج والطلاق لتوعية الشباب والشابات سلفا بحقوقهم وواجباتهم ودوره الاجتماعي. 8. تعزيز دور القضاء في كوردستان في محاربة ظاهرة العنف ضد المراة. 